\title{
HUBUNGAN KARAKTERISTIK REMAJA DENGAN PERILAKU BULLYING PADA SISWA SMP DI KOTA PADANG
}

\author{
Hermalinda ${ }^{1}$, Deswita ${ }^{1}$ \& Elvi Oktarina ${ }^{1}$ \\ 1) Fakultas Keperawatan Univeritas Andalas, Kampus Unand Limau Manis, Padang, \\ Sumatera Barat, Indonesia, 25163 \\ Email: hermalinda.herman.ns@gmail.com
}

\begin{abstract}
Bullying is a phenomenon that is common and universal problems in school-age children. Bullying can cause serious/ negative effects concerning the mental health and child welfare. This study aimed to identify the prevalence of bullying in junior high school students in the city of Padang. The study design was descriptive analytic with cross sectional study. Samples are the students of SMP Negeri 31 Padang, SMPN 28 Padang, SMP Muhammadiyah 7 Padang, and SMP Kartika 1-7 Padang with 340 samples. These samples were taken by simple random sampling technique. Data collection tool is questionnaire which consisting of questions on the general data and child bullying behavior questionnaires. Data were analyzed by using Mann Whitney test and Kruskal Wallis. Research shows that almost half of the students' bullying behavior was verbal bullying, followed by physical bullying and the last was social bullying. There are differentiations regarding bullying behavior by gender and socio-economic. It is expected to develop a research that aimed at the prevention of bullying behavior early on and special interventions which focused on children with low socioeconomic status.
\end{abstract}

Kata kunci: Pre-Menstrual Syndrom, Relaksasi, Guided Imagery

\begin{abstract}
ABSTRAK
Bullying merupakan fenomena yang umum dan masalah yang universal pada anak usia sekolah. Bullying dapat menimbulkan efek yang serius/ negatif terhadap kesehatan mental dan kesejahteraan anak. Penelitian ini bertujuan untuk mengidentifikasi prevalensi perilaku bullying pada siswa SMP di Kota Padang. Desain penelitian adalah deskriptif analitik dengan pendekatan cross sectional study. Sampel adalah siswa SMP Negeri 31 Padang, SMP 28 Padang, SMP Muhammadiyah 7 Padang dan SMP Kartika 1-7 Padang dengan jumlah sampel 340 orang, sampel diambil dengan teknik simple random sampling. Alat pengumpulan data adalah kuesioner yang terdiri atas pertanyaan tentang data umum anak dan kuesioner perilaku bullying. Data dianalisis dengan menggunakan uji Mann Whitney dan Kruskall Wallis. Hasil Penelitian menunjukkan bahwa perilaku bullying yang dilakukan siswa hampir sebagian adalah bullying verbal, diikuti dengan bullying fisik dan terakhir bullying sosial. Terdapat perbedaan antara perilaku bullying dengan jenis kelamin dan sosial ekonomi. Diharapkan dikembangkan suatu penelitian yang bertujuan untuk melakukan pencegahan terhadap perilaku bullying dengan segera dan intervensi khusus di fokuskan pada anak dengan status sosial ekonomi rendah.
\end{abstract}

Kata kunci: Pre-Menstrual Syndrom, Relaksasi, Guided Imagery 


\section{PENDAHULUAN}

Bullying adalah perilaku yang tidak diinginkan/ perilaku agresif pada anak usia sekolah yang terjadi karena ketidakseimbangan kekuatan. Perilaku dilakukan berulang atau berpotensi dilakukan berulang kali, dan setiap waktu. Bullying terdiri atas tindakan seperti membuat ancaman, menyebarkan rumor, menyerang secara fisik/verbal, dan mengasingkan seseorang dari kelompok. Bullying dapat terjadi melalui orang atau melalui teknologi (CDC, 2014).

Bullying merupakan fenomena yang umum dan masalah yang universal pada anak usia sekolah (Tsitka et al, 2014). Prevalensi perilaku bullying pada anak di Kanada adalah sekitar 9\% $21 \%$. Suatu penelitian yang meneliti tentang perilaku anak perempuan dan laki-laki usia 12-17 tahun pada 5 negara: Cambodia, Indonesia, Nepal, Pakistan dan Vietnam, didapatkan hasil bahwa $71 \%$ anak, baik laki-laki/perempuan mempunyai pengalaman kekerasan dalam 6 bulan terakhir di sekolah ((ICRW, 2014).

Hasil penelitian menunjukkan bahwa 29,8\% anak usia 7-12 tahun dibully sejak pertama masuk sekolah. Bentuk tindakan yang sering dirasakan adalah verbal $23,6 \%$, fisik $29 \%$, dan kehilangan. Sebanyak 8,1\% anak, dibully setiap hari atau setiap minggu (OKN, 2012). Dari 1075 anak usia sekolah di Kota Pelotas, RS Brazil, terdapat 17,6\% anak dengan perilaku bullying. Tipe yang paling banyak adalah verbal, diikuti fisik, emosional dan seksual (de Moura, Cruz, \& de Avila Quevedo, 2011). Di Indonesia, bentuk kekerasan yang terjadi adalah fisik (memukul, menampar, menendang), emosional, dikunci di toilet dan jenis kekerasan lainnya (ICWR, 2014).
Bullying dapat menimbulkan efek yang serius/ negatif terhadap kesehatan mental dan kesejahteraan anak (CDC, 2014; Tsitsika et al, 2014). Dampak negatif dari bullying pada anak yang menjadi pelaku atau korban terdiri atas depresi, kecemasan, penyalahgunaan zat, fungsi sosial rendah, rendahnya prestasi akademik dan kurang perhatian. Orang yang sering melakukan bullying dan menjadi korban mempunyai risiko untuk bunuh diri (CDC, 2014).

Remaja yang menjadi korban bullying melaporkan masalah fisik dan mental dibandingkan dengan anak yang bukan korban. Anak perempuan yang menjadi korban menunjukkan masalah spesifik seperti sakit kepala dan gangguan tidur (Biebl et al, 2011). Depresi merupakan efek bullying jangka panjang, hal ini dapat dilihat pada penelitian yang dilakukan oleh Due et al (2009), dimana terpapar dengan bullying meningkatkan risiko depresi pada usia dewasa muda.

Faktor risiko bullying terdiri atas variabel psikologis, emosional, biologis dan faktor lingkungan. Bullying merupakan kontruksi komplek yang terlihat dan dapat mempengaruhi jumlah serta tergantung pada faktor anak seperti faktor psikologis, kognitif, emosi dan lingkungan sekitar yang spesifik seperti harapan orang tua dan status sosial ekonomi (Liu \& Graves, 2011). Jumlah sibling dan kurangnya keterlibatan orangtua merupakan faktor keluarga yang berisiko meningkatkan perilaku bullying (Wolke \& Skew, 2012).

Efek bullying memberikan efek yang jangka panjang pada kesehatan anak. Diharapkan adanya upaya yang berfokus tidak hanya dalam mengurangi prevalensinya tetapi juga melakukan pendidikan tentang bullying serta 
mengembangkan riset yang bertujuan untuk mengidentifikasi prediktor dari bullying (Tsitsika et al, 2014; Liu \& Graves, 2011).

Survey pendahuluan yang dilakukan diapatkan data kasus bullying di kota Padang. Data dari Polresta Kota Padang sepanjang tahun 2014 sampai 2015 angka laporan kasus bullying cukup tinggi di sekolah baik di tingkat SD, SMP, SMA yaitu sebanyak 72 kasus bullying yang dilaporkan berupa tindakan penganiayaan, pemalakan dan pelecehan, dan perbuatan tidak menyenangkan. Berdasarkan hal diatas, dirasakan perlu adanya suatu penelitian yang bertujuan untuk mengindentifikasi faktor-faktor yang berhubungan dengan perilaku bullying pada remaja/ siswa SMP di Kota Padang.

\section{METODE}

\section{Desain penelitian:}

Penelitian ini mengggunakan desain descriptive analytic dengan menggunakan pendekatan cross sectional study. Populasi penelitian ini adalah seluruh siswa menengah tingkat pertama (SMP) di Kota Padang. Pada penelitian ini, dipilih empat SMP yang ada di Kota Padang, dengan jumlah populasi adalah 2257. Pengambilan sampel dalam penelitian ini menggunakan teknik probability sampling dengan pendekatan proportional random sampling. Berdasarkan hasil perhitungan tersebut maka besar sampel yang diambil adalah 340 orang. Penelitian dilaksanakan di empat sekolah tingkat menengah pertama (SMP) baik negri ataupun swasta yang ada di kota Padang, yang dilaksanakan mulai dari bulan Juni s/d Desember 2016. Variabel dependen adalah perilaku bullying dan variabel independen adah jenis kelamin dan sosial ekonomi.

Penelitian ini telah mendapatkan pertimbangan etik dari komite etik Fakultas Kedokteran Universitas Andalas. Sebelum pengumpulan data dilakukan, responden diberikan penjelasan tentang penelitian (informed concent) dan meminta kesediaan responden untuk berpartisipasi dalam penelitian. peneliti menjamin kerahasiaan identitas responden.

\section{Alat Pengumpulan data:}

Data dikumpulkan dengan menggunakan kuesioner. Kuesioner terdiri atas beberapa komponen, diantaranya adalah:

a. Data demografi yang mencakup nama, usia, jenis kelamin, status ekonomi, dan kelas.

b. Untuk bullying (pelaku) menggunakan kuesioner Adolescent Peer Relations Instrument (Hamburger, Basile \& Vivolo, 2011). Kuesioner yang digunakan adalah kuesioner sesi A tentang perilaku bullying. Kuesioner ini terdiri atas 18 pernyataan dengan alternatif jawaban: tidak pernah terjadi (1), kadang-kadang (2), 1 atau 2 kali dalam 1 bulan (3), 1 kali seminggu (4), lebih dari 1 kali seminggu (5) dan setiap hari (6).

Analisa data yang dilakukan adalah analisis univariat dan bivariat. Analisa univariat dimaksudkan untuk mendeskripsikan hasil penelitian berdasarkan karakteritik responden. Analisa bivariat dalam penelitian ini ditujukan untuk mengetahui hubungan karakteristik remaja dengan perilaku bullying pada remaja. Analisis data menggunakan program SPPS. Hasil analisis normalitas data didapatkan data 
tidak berdistribusi normal sehingga uji statistik yang digunakan adalah uji non parametrik yaitu Mann Whitney dan
a. Prevalensi Perilaku Bullying pada Remaja

Tabel 1. Prevalensi perilaku bullying pada remaja (remaja sebagai pelaku)

\begin{tabular}{|c|c|c|c|c|c|c|}
\hline \multirow[t]{2}{*}{ Bullying } & \multicolumn{6}{|c|}{ Persentase (\%) } \\
\hline & 1 & 2 & 3 & 4 & 5 & 6 \\
\hline \multicolumn{7}{|l|}{ Bullying verbal } \\
\hline $\begin{array}{l}\text { Mengganggu siswa lain dengan mengatakan } \\
\text { sesuatu yang buruk }\end{array}$ & 36.2 & 50.0 & 5.0 & 1.8 & 3.5 & 3.5 \\
\hline $\begin{array}{l}\text { Memberikan julukan yang tidak baik terhadap } \\
\text { seorang siswa }\end{array}$ & 42.1 & 42.6 & 6.5 & 1.5 & 3.2 & 4.1 \\
\hline Membuat olokan tentang seorang siswa & 52.9 & 40.3 & 2.9 & 0.6 & 1.8 & 1.5 \\
\hline Memaki/mengumpat seorang siswa & 67.1 & 28.2 & 2.4 & 9 & 1.2 & 0.3 \\
\hline Mengejek penampilan seorang siswa & 58.8 & 35.0 & 2.6 & 1.2 & 1.5 & 0.9 \\
\hline $\begin{array}{l}\text { Mengolok seorang siswa dengan sebutan- } \\
\text { sebutan }\end{array}$ & 49.1 & 42.4 & 2.6 & 1.8 & 1.8 & 2.4 \\
\hline \multicolumn{7}{|l|}{ Bullying Sosial } \\
\hline Meminta teman untuk melawan siswa lain & 77.6 & 19.1 & 1.5 & 0.6 & 0.6 & 0.6 \\
\hline $\begin{array}{l}\text { Menyebarkan gosip tentang seorang siswa } \\
\text { kepada teman-teman di sekolah agar dia } \\
\text { mendapat masalah }\end{array}$ & 75.3 & 19.4 & 3.2 & 0.6 & 0.6 & 0.9 \\
\hline $\begin{array}{l}\text { Mengajak siswa lain untuk membuat gosip } \\
\text { tentang seorang siswa }\end{array}$ & 81.5 & 16.2 & 0.6 & 0.9 & 0.3 & 0.6 \\
\hline Mengajak siswa lain menjauhi seorang siswa & 84.1 & 14.4 & 0.3 & 0.9 & 0 & 0.3 \\
\hline $\begin{array}{l}\text { Meninggalkan suatu aktifitas atau permainan } \\
\text { dengan sengaja }\end{array}$ & 58.2 & 36.5 & 2.9 & 0.9 & 0.9 & 0.6 \\
\hline $\begin{array}{l}\text { Melototi siswa lain agar mereka tidak mau } \\
\text { mendekati saya }\end{array}$ & 80.6 & 16.5 & 1.5 & 0.9 & 0.3 & 0.3 \\
\hline \multicolumn{7}{|l|}{ Bullying fisik } \\
\hline Mendorong siswa lain & 42.6 & 48.8 & 2.9 & 1.8 & 1.5 & 2.4 \\
\hline $\begin{array}{l}\text { Sengaja menabrak siswa lain ketika mereka } \\
\text { berjalan }\end{array}$ & 60.6 & 32.9 & 3.5 & 0.9 & 0.9 & 1.2 \\
\hline $\begin{array}{l}\text { Berkelahi secara fisik dengan siswa lain } \\
\text { karena saya tidak menyukainya }\end{array}$ & 75.9 & 20.0 & 2.4 & 1.2 & 0.3 & 0.3 \\
\hline Saya menampar atau memukul siswa lain & 76.8 & 20.6 & 0.6 & 0.6 & 0.6 & 0.9 \\
\hline Melemparkan sesuatu kepada siswa lain & 53.2 & 39.4 & 2.4 & 2.1 & 1.5 & 1.5 \\
\hline $\begin{array}{l}\text { Mengancam, menggertak dan menyakiti } \\
\text { siswa lain secara fisik }\end{array}$ & 80.6 & 16.5 & 1.5 & 0.9 & 0.3 & 0.3 \\
\hline \multicolumn{7}{|l|}{ Keterangan: } \\
\hline \multicolumn{7}{|l|}{ 1. Tidak pernah } \\
\hline \multicolumn{7}{|l|}{ 2. Kadang-kadang } \\
\hline \multicolumn{7}{|l|}{ 3. 1 atau 2 kali dalam 1 bulan } \\
\hline \multicolumn{7}{|l|}{ 4. 1 kali se-minggu } \\
\hline \multicolumn{7}{|l|}{ 5. 1 kali se-minggu } \\
\hline 6. Setiap hari & & & & & & \\
\hline
\end{tabular}

Kruskall Wallis.

HASIL

\section{Hasil Penelitian}

Pada tabel diatas dapat dijelaskan bahwa persentase perilaku bullying yang dilakukan siswa hampir sebagian adalah bullying verbal, diikuti dengan bullying 
fisik dan terakhir bullying sosial. Sebagian atau sebesar $50 \%$ siswa menyatakan bahwa kadang-kadang mengganggu siswa lain dengan mengatakan sesuatu yang buruk, $42,6 \%$ kadang-kadang siswa memberikan julukan yang tidak baik terhadap seorang siswa, dan 42,4\% kadang-kadang siswa mengolok seorang siswa dengan sebutan-sebutan. Ada sebagian kecil atau $4,1 \%$ siswa yang setiap hari memberikan julukan yang tidak baik terhadap seorang siswa. Untuk bullying sosial yang paling banyak dilakukan oleh siswa adalah meninggalkan suatu aktifitas atau permainan dengan sengaja (36,5\%).

Bullying fisik yang banyak dilakukan oleh siswa adalah mendorong siswa lain $(48,8 \%)$, melemparkan sesuatu kepada siswa lain $(39,4 \%)$ dan sebesar $32,9 \%$ sengaja menabrak siswa lain ketika mereka berjalan. Hanya sebagian kecil $(0.9 \%)$ siswa yang setiap hari menampar atau memukul siswa lain.

b. Analisis Hubungan Faktor Jenis Kelamin dan Sosial Ekonomi dengan Perilaku Bullying

Tabel dibawah ini menjelaskan tentang analisis faktor-faktor yang berhubungan dengan perilaku bullying.
Pada tabel 2 dapat dilihat bahwa perilaku bullying baik lebih tinggi pada laki-laki dibandingkan dengan perempuan. Bullying juga lebih tinggi pada siswa dengan status sosial ekonomi menengah dibanding dengan status sosial ekonomi rendah dan tinggi. Hasil uji statistik didapatkan bahwa terdapat perbedaan yang bermakna antara jenis kelamin dan status sosial ekonomi dengan perilaku bullying dengan $p$ value masing-masing adalah 0.000 dan 0.016 .

\section{PEMBAHASAN}

\section{b. Prevalensi perilaku bullying}

Hasil penelitian menunjukkan bahwa sebagian besar atau sebesar $89,4 \%$ siswa sebagai pelaku bullying dan $94,1 \%$ sebagai korban. Hal ini menunjukkan prevalensi perilaku bullying yang tinggi pada remaja, walaupun skor perilaku bullying yang dianalisis rendah. Hasil analisis didapatkan bahwa frekuensi perilaku bullying yang dilakukan siswa adalah kadang-kadang hanya sebagian kecil siswa yang melakukan bullying dengan intensitas/frekuensi setiap hari.

Hasil penelitia yang sama menunjukkan prevalensi perilaku bullying

Tabel 2 Analisis hubungan faktor karakteristik remaja, status sosial ekonomi dan faktor keluarga dengan perilaku bullying (pelaku dan korban)

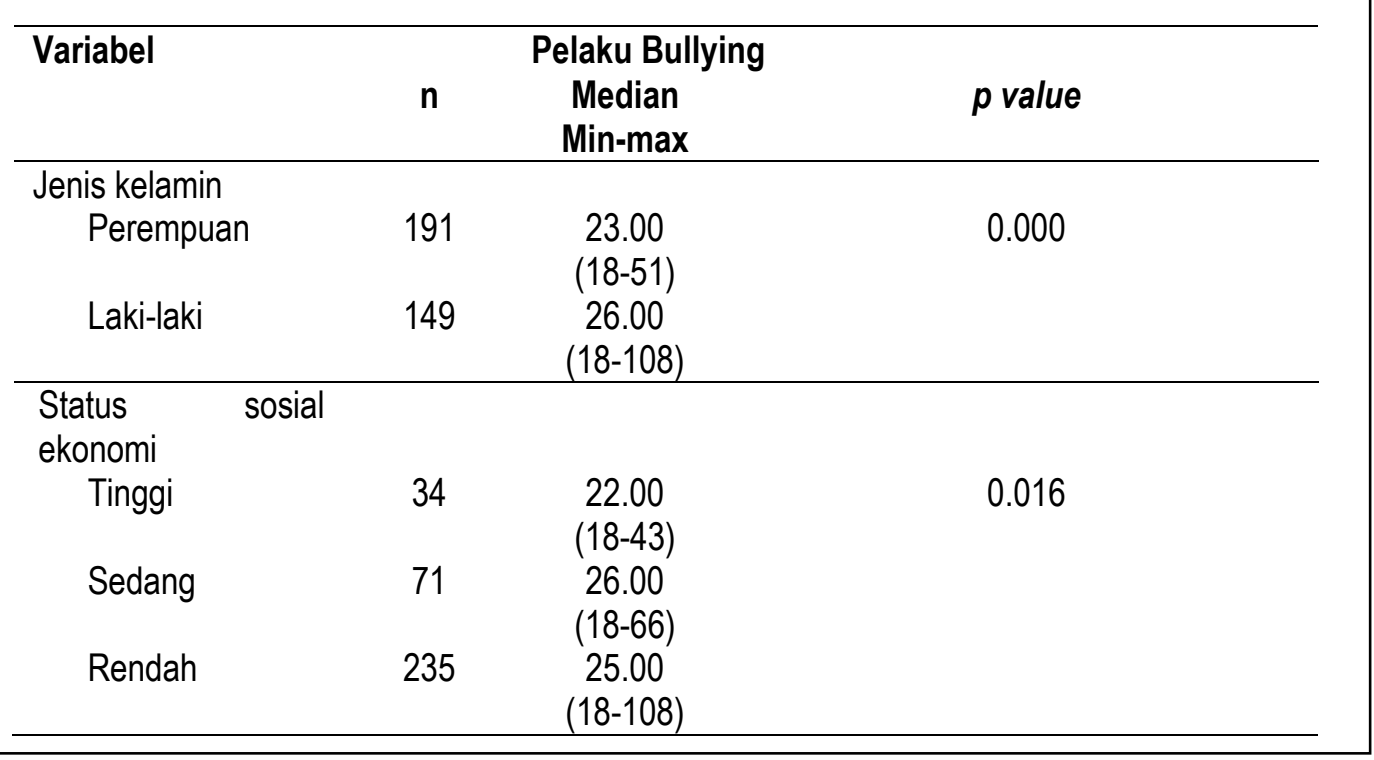


yang tinggi di kalangan remaja Brasil (Pigozi \& Machado, 2015). Sementara sekitar $60 \%$ murid di Mesir dan satu per tiga murid di Libya, Maroko dan Tunisia melaporkan perilaku bullying dalam 1 bulan terakhir (Abdirahman, Fleming \& Jacobsen, 2013). Hasil yang cukup berbeda dilaporkan di Nigeria dimana hasil analisis data menunjukkan bahwa bullying terjadi kurang dari setengah sampel (28\%) sementara $42 \%$ murid melakukan bullying terhadap anak lain (Owuamanam \& Makinwa, 2015).

Bullying adalah penyalahgunaan kekuasaan dari seseorang terhadap orang lain melalui perilaku agresif yang berulang. Bagi pelaku bullying, kekuasaan dapat timbul dari kekuatan fisik, dan kematangan, status tertinggi dalam kelompok, mengetahui kelemahan anak lain, atau mengerahkan dukungan dari anak lain (Fortinash \& Worret, 2012).

Menurut teori perkembangan psikososial oleh Erikson, remaja berada pada masa pengembangan identitas diri. Pada masa remaja, anak mulai menilai diri mereka sebagai individu yang berbeda, unik dan terpisah dari setiap individu yang lain. Periode remaja awal dimulai dengan awitan pubertas dan berkembangnya stabilitas emosional dan fisik yang relatif pada saat remaja hampir lulus SMU (Hockenbbery \& Wilson, 2009).

Salah satu tugas perkembangan remaja adalah menerima keadaa fisik dan menggunakan tubuhnya secara lebih efektif. Adanya perubahan pada bentuk dan fungsi tubuh dapat mengakibatkan masalah pada konsep diri remaja (Muhith, 2015).

Pada tabel 1 dapat dijelaskan bahwa persentase perilaku bullying yang dilakukan siswa hampir sebagian adalah bullying verbal, diikuti dengan bullying fisik dan terakhir bullying sosial. Hal ini menunjukkan bahwa remaja lebih cenderung untuk melakukan kekerasan secara verbal terhadap teman sebaya.

Hal yang sama ditunjukkan pada penelitian di Kota Pelotas, RS Brazil, dimana Dari 1075 anak usia sekolah, terdapat $17,6 \%$ anak dengan perilaku bullying. Tipe yang paling banyak adalah verbal, diikuti fisik, emosional dan seksual (de Moura, Cruz, \& de Avila Quevedo, 2011). Sementara, studi yang dilakukan oleh Owuamanam dan Makinwa tahun 2015 menunjukkan bahwa kejadian yang paling banyak adalah bentuk emosional bullying.

Hasil penelitian ini berbeda dengan penelitian sebelumnya bahwa 29,8\% anak usia 7-12 tahun dibully sejak pertama masuk sekolah. Bentuk tindakan yang sering dirasakan adalah verbal $23,6 \%$, fisik $29 \%$, dan kehilangan. Sebanyak $8,1 \%$ anak, dibully setiap hari atau setiap minggu (OKN, 2012). Sama halnya dengan penelitian yang dilakukan di lima negara Asia salah satunya Indonesia dimana bentuk kekerasan yang terjadi adalah fisik (memukul, menampar, menendang), emosional, dikunci di toilet dan jenis kekerasan lainnya (ICWR, 2014).

\section{c. Hubungan Faktor Jenis Kelamin dengan Perilaku Bullying.}

Hasil penelitian menunjukkan bahwa perilaku bullying lebih tinggi pada laki-laki dibandingkan dengan perempuan. Persentase perilaku bullying lebih besar pada laki-laki (9,9\% untuk SMP dan $12,1 \%$ untuk SMA) dibandingkan perempuan $(5,0 \%$ untuk SMP dan 4,8\% untuk SMA) (MMWR, 2011). Beberapa studi sebelumnya juga menunjukkan bahwa anak laki-laki lebih banyak menjadi pelaku atau korban bullying seperti bullying fisik, verbal dan 
bentuk bullying lainnya (Jansen et al, 2011; Tsitsika et al, 2015).

Anak perempuan pada penelitian ini lebih sedikit menjadi pelaku atau korban bullying. Anak perempuan lebih sering tidak terlibat langsung terhadap perilaku bullying (Wolke \& Skew, 2012; Tsitsika et al, 2014). Menurut survey kesehatan dunia didapatkan bahwa perempuan mempunyai kecendrungan lebih besar sebagai korban $(29,8 \%$ untuk SMP dan $17,8 \%$ untuk SMA) dibandingkan laki-laki $(24,1 \%$ untuk sekolah menengah dan $13,3 \%$ untuk SMA) (MMWR, 2011). Namun, hal yang berbeda ditemukan di Cluj-Napoca, dimana anak perempuan lebih banyak menunjukkan perilaku bullying dibandingkan laki-laki (Beldean-Galea, Jurcau, \&Tigan, 2010).

Hasil penelitian ini berbeda dengan temuan yang dilakukan di empat negara yaitu di Mesir, Lybia, Tunisia, dan Maroko. Hasil studi menunjukkan bahwa anak laki-laki lebih banyak menjadi korban bullying dari kelompok dari pada anak perempuan (Abdirahman, Fleming, \& Jacobsen, 2013). Anak laki-laki lebih sering menjadi korban bullying, dan yang paling banyak adalah kekerasan fisik (Silvi et al, 2013).

Perilaku bullying menunjukkan perbedaan yang signifikan berdasarkan jenis kelamin pada penelitian ini. Penelitian sebelumnya juga menunjukkan adanya perbedaan yang signifikan keterlibatan dalam bullying anatara gender dan peran yang dilakukan (Beldean-Galea, Jurcau, \&Tigan, 2010; Silva et al, 2013; Carleby et al, 2013). Namun, beberapa studi menunjukkan tidak ada perbedaan yang signifikan antara jenis kelamin terhadap perilaku dan korban bullying (MMWR, 2011; Velki, 2012).

Anak laki-laki dan perempuan mempunyai kecendrungan yang berbeda dalam bantuk perilaku bullying. Anak perempuan cenderung menggertak secara fisik dan lebih sering terlibat dalam agresi relasional. Bentuk bullying diantaranya dengan sengaja menjauhi dan mengeluarkan korban dari pertemanan. Fitnah, menyebarkan rumir dan berbbuat curang merupakan bentuk bullying relasional (Fortinash \& Worret, 2012).

\section{c. Hubungan Faktor Status Ekonomi dengan Perilaku Bullying}

Pada hasil penelitian ini perilaku bullying lebih tinggi pada siswa dengan status ekonomi menengah dan rendah dan skor perilaku bullying lebih rendah pada anak dari sosial ekonomi tinggi. Hasil uji statistik terdapat perbedaan yang signifikan perilaku bullying pada anak dari status sosial ekonomi rendah dan menengah dengan anak dari status sosial ekonomi tinggi.

$\begin{array}{llr}\text { Suatu studi berupa sistematik } \\ \text { review } & \text { dilakukan } & \text { dengan }\end{array}$
mengidentifikasi 28 hasil penelitian tentang perilaku bullying di sekolah dan menilai status sosial ekonomi. Hasil random secara acak dapat disimpulkan bahwa status sosial ekonomi mempunyai hubungan yang lemah terhadap perilaku bullying. Perilaku bullying lebih sedikit kemungkinan berasal sosial ekonomi yang tinggi (Tippet \& Wolke, 2014).

Hasil penelitian sebelumnya menunjukkan bahwa perilaku bullying lebih banyak pada remaja dengan status ekonomi yang rendah. Anak Amerika Afrika Latin dan anak-anak yang hidup dalam kemiskinan mempunyai kecendrungan yang tinggi terhadap bullying (Shetgiri et al, 2012). Anak dengan status sosial ekonomi rendah lebih banyak menunjukkan perilaku bullying, korban, dan hanya sedikit yang 
tidak terlibat (Jansen, et al. 2011). Namun, berdasarkan penelitian Copelanda et al tahun 2014, bullying merupakan pengalaman yang paling umum pada anak pada semua tingkat status sosial ekonomi, dan kelompok ras.

Anak-anak dari sosek rendah dan anak yang sekolah dengan lingkungan sekolah yang kurang baik mempunyai risiko untuk perilaku bullyin (Jansen et al, 2012). Ada interaksi yang signifikan secara statistik antara bullying dan status sosial ekonomi, oleh karena itu bullying meningkatkan risiko depresi pada individu dengan status ekonomi rendah sementara terdapat hubungan yang lemah antara korban bullying dan gejala depresi pada individu dengan status ekonomi yang baik. Hasil penelitian menunjukkan bahwa bullying mengakibatkan efek jangka panjang yang sangat serius pada kesehatan anak. Paparan terhadap bullying juga dapat mempengaruhi kualitas sosial dalam kesehatan dewasa (Due et al, 2009). Oleh karena itu, beberapa studi menganjurkan untuk melakukan pencegahan terhadap perilaku bullying dengan segera dan intervensi khusus di fokuskan pada anak dengan status sosial ekonomi rendah (Jansen et al, 2012).

\section{KESIMPULAN DAN SARAN}

Perilaku bullying yang dilakukan siswa hampir sebagian adalah bullying verbal, diikuti dengan bullying fisik dan terakhir bullying sosial. Perilaku bullying menunjukkan perbedaan yang signifikan berdasarkan jenis kelamin dan status sosial ekonomi. Diharapkan dikembangkan suatu penelitian yang bertujuan untuk melakukan pencegahan terhadap perilaku bullying dengan segera dan intervensi khusus di fokuskan pada anak dengan status sosial ekonomi rendah

\section{REFERENCES}

Abdirahman, H., Fleming, L.C \& Jacobsen, K.H. (2013). Parental involvement and bullying among middleschool students in North Africa. Eastern Mediterranean Health Journal, 19 (3): 227-233.

Astuti, P.R. (2008) . Meredam Bullying : 3 cara efektif menanggulangi kekerasan pada anak. Jakarta: Grasindo.

Beldean- Galea, L.E., Jurcau, N., \& Tigan, S.I. (2010). Frequency of Bullying Behaviours in Secondary Schools in ClujNapoca. Applied Medical Informatics, 27( 4): 62-66.

Bielb, S.J.W., Dailalla, L.F., Davis, E.K., Lynch, K.A., \& Shinn, S.O. 2011. Longitudinal association among peer victimization and physical and mental health problem. Journal of Pediatric sychology, 36 (8): 868-877.

Brown, S.L. Birch, D.A., \& Karcherla, V. 2005. Bullying perspective attitude and recomendations of 9 to 13 year old attending health education centers in the United State. Journal Science Health, 75 (10): 384-82.

Carlerby, H., Viitasara, E., Knutsson, A., \& Gadi, K.G. (2013). How bullying involvement is associated with the distribution of parental background and with subjective health complaints among swedish boys and girls. Soc Indic Res, (2013) 111:775783, DOI 10.1007/s11205-0120033-9.

Copelanda, W.a., Wolke, D., Lereya, S.T., Worthman, C., Costello, E.J. (2014). Childhood bullying 
involvement predicts low-grade systemic inflammation into adulthood. PNAS 111 (21), 7570-7575.

Dake, J.A., Price, J.H., Telljohann, S.K., \& Funk, J.B. (2003). Teacher perceptions and practices regarding School bullying prevention. The Journal of school Health, 73 ( 9): 347-354.

De Moura, D.R., Cruz, A.C.N., \& de Avila Quevedo, L. (2011). Prevalence and charactristic of school age bullying victims. Journal de Pediatria, 87 (1), 1923.

Driessens,

C.M.E.F.

(2015). Extracurricular activity participation moderates impact of family and school factors on adolescents' disruptive behavioural problems. BMC Public Health (2015) 15:1110: 113, DOI 10.1186/s12889-0152464-0

Due, P., Damsgoard, M.T., Lund, R., \& Holstein, B.E. (2009). Is bullying equal for rich and poor children?

A study of bullying and depression from age 15 to 27 . European Journal of Public Health, 9 (5), 464-469.

Flyint, S.W. Morton, R.C. Alabama. (2006) Elementary principals perception of bullying. Education, 2, 187-191.

Fortinash, K.M., \& Worret, G. (2012). Psychiatric mental health nursing, Fifth Edition, ISBN 9780-323-07572-5. Elsevier: Philadelphia

Hamburger ME, Basile KC, Vivolo AM. (2011). Measuring bullying victimization, perpetration, and bystander experiences: A compendium of assessment tools. Atlanta, GA: Centers for Disease Control and Prevention, National Center for Injury Prevention and Control.

Hockenberry, M. J \& Wilson, D. (2009). Wong's essential of pediatric nursing, $8^{\text {th }}$ edition. St. Louis: Mosby Year Book.

International Center for Research on Women (ICWR). 2014. Are school safe and gender aqual space: Findings from a baseline study of school related gender based violence in five countries Asia. Diakses dari www.icwr.org, pada tanggal 18 Maret 2016 pukul 05.53.

Jansen, D. EMC., Veenstra, R., Ormel, J., Verhulst, F.C., \& Reinjneveld, S.A. (2011). Early risk factor for being a bully, victim, or bully/victim inlate elementary and early secondary education: the longitudinal TRAILS study. BMC Public Health, 11, 440.

Jansen, P.W, Verlinden, M., Berkel,D., et al. 2012. Prevalence of bullying and victimization among children in early elementary school: Do family and school neighbourhood socioeconomic status matter?. BMC Public Health, 12 (494).

Liu, J., \& Graves, N. (2011). Childhood bullying: A riview of construct, context and nursing implication. Public Health Nurse, 28 (6) : 556-568.

Marta Angélica lossi Silva, M.A., Pereira, B., Mendonça, B., Nunes, B., \&de Oliveira, W.A. The Involvement of Girls and Boys with Bullying: An Analysis of Gender Differences. Ciência \& Saúde Coletiva, 20(11):3509- 
3522, DOI: $10.1590 / 1413-$ 812320152011.05292014

Merril, R.M., \& Hanson, C.L. (2016). Risk and protective factors associated with being bullied on school property compared with cyberbullied. BMC Public Health 16 (145): 1-10, DOI 10.1186/s12889-016-2833-3

MMWR. 2011. Bullying among middle school and high school students - massachusetts, 2009. Morbidity and Mortality Weekly Report (MMWR), 60 (15), 465471.

Muhith, A. 2015. Pendidikan keperawatan jiwa: Teori dan aplikasi. CV Andi OFFSET: Jakarta.

National Center for Injury Prevention and Control (CDC). 2014. The relationship between bullying and suicide: What we know and what it mean for school. Center for Disease Control and Prevention, National Center for Injury and Preventioan and Control, devision of violence, Chamblee. Diakses dari www.cdc.gov pada tanggal 18 Maret 2016 pukul 06.53.

O'connel,J (2003) Bullyingat school. California : Departement of education.

Olweus,D (2003) Bullying at school. USA : Blackwell publishing.

Our Kinds Network (OKN). 2012. Bullying prevention and support among school age children and youth: A riview of the literature. Halton Kids Our Kids Network, School Year Committe.

Owuamanam, D. \& Makinwa, V.I. (2015). Prevalence of bullying among secondary school students in ondo state, nigeria.
European Scientific, 11 (20): 1857-7431.

Pigozi, P.M., Machado, A.L. (2015). Bullying during adolescence in Brazil: an overview. International Journal of Environmental Research and Public Health, 10, 6820-6831; doi:10.3390/ijerph10126820.ISS N 1660-4601.

Polit, D. F., \& Hungler, B. P. (2005). Nursing research: Principles and methods. Philadelphia: Lippincott Williams \& Wilkins.

Sastroasmoro, S., \& Ismael, S. (2010). Dasar-dasar metodologi penelitian klinis. Edisi 3. Jakarta: Sagung Seto.

Setiawan, D. (2014). KPAl: Kasus bullying dan pendidikan karakter. Diakses dari www.kpai.go.d, pada tanggal 17 Maret 2016 pukul 09.56.

Shaheen, A, Nassar, O, Saleh, M., \& Arabiat, D. (2014). Understanding of school related factors associated with emotional health and bullying behavior among jordanian adolescents. Iranian $J$ Publ Health, 43 (11): 1528-1536.

Shaheen, A., Nassar, O., \& Satet, M. (2014). Understanding of school related factor associated with emotional health and bullying behavior among Jordanian Adolescent. Iranian Journal Public Health, 43(11): 15281536.

Shetgiri, R., Lin, H., Avila, R.M., Flores, G. (2012). Parental characteristics associated with bullying perpetration in us children aged 10 to 17 years. American Journal of Public Health, 102 (12) : 2280-2286. 
Smokowski, P.R., Cotter, K.L., Robertson, C., \& Guo, S. (2013). Demographic, psychological and social environment correlates of bullying victimization and school hassles in rural youth. Journal of Criminology, 2013, 13 page.

Tim Yayasan Semai Jiwa Amini (Sejiwa). 2008. Bullying: mengatasi kekerasan di sekolah dan di lingkungan sekitar anak. Diakses dari www.book.google.co.id pada tanggal 17 Maret 2016 pukul 10.18 .

Tippet, N., Wolke, D. (2014). Socioeconomic status and bullying: a meta-analysis. American Journal of Public Health, 104( 6): E48-e59.

Tsitsika, A.K et al. (2014). Bullying behavior in children and adolescent and ongoing story. Frontiers in Public Health, 2, 1-4.

Velki, T. (2012). A comparison of individual characteristics and the multiple contexts for children with different bullying status: an ecological perspective. International Journal of Arts \& Sciences,. ISSN: 1944-6934 :5(7):89-112 (2012), 89-112

Wolke, D., \& Skew, A.J. (2012). Family factors, bullying victimization and wellbeing in adolescent. Longitudinal and Life Course Studies, 3 (1), 101-119.

Wolke, D., Woods, S., Bloomfield, L., Karstoudt, L. (2001). Bullying involvement in primary school and common health problems. Arch Dis Child, 85, 197-201.

Zhou, Y., Guo, L., Lu, C., et al. (2015). Bullying as a Risk for Poor Sleep Quality among High School Students in China. PLOS ONE, 10(3): $\quad$ e0121602 doi:10.1371/journal: 1-14 